\title{
Extraction of Bioactive Compounds from Mango Peels Using Green Technology
}

\author{
S. Tunchaiyaphum, M. N. Eshtiaghi, and N. Yoswathana
}

\begin{abstract}
Mango peels, wastes generated from fruit can processing, are a good source of functional ingredients such as phenolic compounds that has potential antioxidant properties. This study investigated the extraction of phenolic compounds from mango peels using subcritical water extraction (SCW). Experiments were performed in a batch laboratory-built equipment $(50 \mathrm{ml}$ volume of vessel) immersed in oil bath and temperatures ranging from 160 to $220{ }^{\circ} \mathrm{C}$, extraction time of 30 to 120 min., material particle sizes of 30 to 70 mesh, solid to water ratio of $1: 10$ to $1: 50$ and $\mathrm{pH}$ of solution 2 to 8 . The highest phenolic content was obtained $50.25 \mathrm{mg}$ GAE / g DW at the condition as follows: $180{ }^{\circ} \mathrm{C}, 90 \mathrm{~min}$, solid to water ratio as 1:40 and $\mathrm{pH}$ 4. The amount of phenolic compounds from mango peels using SCW extraction was higher than that using soxhlet extraction at extraction time $60 \mathrm{~min}$ as 1.5 times. SCW extraction might be an alternative green technology for phenolic compounds extraction from agricultural wastes which substitute conventional method using organic solvents.
\end{abstract}

Index Terms-Subcritical water extraction, phenolic compounds, mango peels.

\section{INTRODUCTION}

Fruits and vegetables are the major sources of naural antioxidants and contain various kinds of antioxidant compounds such as vitamin C, vitamin E, carotenoids, lutein, and lycopene. Among these compounds, Phenolic compounds represent a majority of natural antioxidants presently identified [1]. It has ability to scavenge free radicals and exhibits antimutagenic, anticarcinogenic, antiglycemic, anticholesterol, anti-inflammatory and antimicrobial properties [2]. Phenolic compounds can be used as ingredients in cosmetics, pharmaceuticals, nutraceuticals and food. For application in food, it can be used to prevent oxidation of food containing high amounts of liquid [3]. Phenolic compounds were found in various fruits and vegetables. Some agricultural wastes from the fruit can industry such peels of mango have been found to be a rich source of antioxidant phenolic compounds [4], [5].

The mango (Mangifera indica L.), which belongs to the family anacardiaceae, is the most cultivated fruit in Thailand. Processed mango products are among the major goods exported from Thailand. Major byproducts of mango processing are peels and seeds, amount of 35 and $60 \%$ of the

Manuscript received March 25, 2013; revised June 3, 2013. This work was supported in part by This work was supported in part by the National Research Council of Thailand (NRCT), Thailand Toray Science Foundation (TTSF) and Faculty of Engineering, Mahidol University.

The authors are with the Mahidol University, Faculty of Engineering, Department of Chemical Engineering, Salaya, Thailand 73170 (e-mail: SRWT_001@ hotmail.com, mohammand.esh@ mahidol.ac.th, nuttawan.yos@mahidol.ac.th). total fruit weight, respectively. The peel and seed of mango has a significant potential benefit due to its powerful antioxidant properties and high content of phenolic compound [6]. The major phenolic compounds of ripe and unripe mango peels were gallic acid, syringic acid, gentisyl-protocatechuic, mangiferin, ellagic acid, and quercetin that these phenolic compounds can be a good source of natural antioxidant and can use in food, pharmaceutical and cosmetics industries.

The conventional methods used currently for phenolic compounds extraction such as soxhlet and maceration. During soxhlet, fresh solvent can repeatedly bring to contact with sample many times and the system remains high temperature. Maceration is very sample method that is just soaking materials in solvent for long time extraction [7]. These techniques use organic solvent (such as methanol, ethanol, ethyl acetate, ether, acetronitride) for extraction. Low extraction efficiency and toxic solvent residues in the extracts occurs when using these technologies. Recently, Subcritical water extraction (SCW) has become an increasing alternative technology in the extraction of phenolic compounds. Subcritical water, also called pressurized (hot water), superheated water or hot liquid water, it refers to water at temperature between 100 and $374{ }^{\circ} \mathrm{C}$ and at a pressure which is high enough to maintain the liquid state (below the critical pressure of $22 \mathrm{MPa}$ ). The most important advantages of SWE over traditional extraction techniques are shorter extraction time, lower cost of the extracting solvent, higher quality of the extraction and environment-friendly [8]. SCW extraction has been used for the extraction of phenolic compounds from potato peel [4]. They demonstrated that the high recoveries of phenolic compounds were obtained 81.83 $\mathrm{mg} / 100 \mathrm{~g}$. wet basis (wb) at $180{ }^{\circ} \mathrm{C}$ and extraction time 30 min., meanwhile these compared to $3 \mathrm{~h}$ extraction with methanol was $49.59 \mathrm{mg} / 100 \mathrm{~g}$. wb) and also SCW found Chlorogenic acid (CGA) (14.59 mg / 100 g. wb) and Gallic acid (GAE) (29.56 mg /100 g. wb). The extraction of phenolic compounds from pomegranate seed residues (PSR) using SCW extraction was reported that the highest total phenolic compounds was obtained at $220{ }^{\circ} \mathrm{C}, 30 \mathrm{~min}$ and solid to water ratio of 1:40 [9]. SCW was used to extraction of polyphenolic compounds from Terminalia chebula Retz.fruits that found the amounts of extracted gallic acid (GA) and ellagic acid (EA) increased with an increasing in subcritical water temperature up to $180{ }^{\circ} \mathrm{C}$, while the highest amount of corilagin (CG) was recovered at $120^{\circ} \mathrm{C}$. Moreover, water volumetric flow rate affected the extraction behavior and concluded the suitable flow rate for extraction of total phenolic compounds was $4 \mathrm{ml} / \mathrm{min}$ [10].

The objective of this work were to extract phenolic compounds from mango peels by subcritical water extraction 
(SCW) according to green technology, also to investigated the effect of extraction parameters on the total phenolic content (TPC) and comparative extraction efficiency with conventional method.

\section{Meterials And Methods}

\section{A. Materials}

Mango peels (Mangifera indica L. cultivar Phalun) are obtained from Malee Sampran Public Co., Ltd., a mango processing manufacturer in Thailand, as by-product.

\section{B. Chemicals}

Folin - Ciocalteu's phenol reagent, gallic acid as phenolic compound standard, citric acid and sodium chloride (adjust $\mathrm{pH}$ ) were purchased from Sigma Chemical Co., Ltd (St. Louise, USA).

\section{Preparation of Plant Samples}

Mango peels were washed and dried in hot air oven at $60{ }^{\circ} \mathrm{C}$ for 6 hours. The dried samples were sieved to obtain sieve sizes of 30, 40, 50 and 70 mesh (particle sizes 600, 425, 300, 212 $\mu \mathrm{m})$. The samples were packed in plastic bags and kept them at $4{ }^{\circ} \mathrm{C}$.

\section{Soxhlet Extraction}

Soxhlet extraction, An amount of mango peels $1 \mathrm{~g}$ was extracted with $95 \%$ ethanol as solvent $40 \mathrm{ml}$ in soxhlet apparatus. This method was carried out at boiling temperature of $95 \%$ ethanol for $0.5,1,2,4$ hours. The extracted solution was collected in round bottom flask. After extraction, the extracted sample was be filtered through filter paper ( No.1) and evaporated using a rotary evaporator (Buchi, Switzerland), then prepared for total phenolic content analysis .

\section{E. Subcritical Water Extraction}

Subcritical water extraction (SCW extraction) was carried out in a laboratory-built equipment (50 $\mathrm{ml}$ volume of vessel) immersed in oil bath. The SCW extraction was conducted at various temperature $\left(160,180,200\right.$, and $\left.220^{\circ} \mathrm{C}\right)$, extraction time (30, 60, 90, and $120 \mathrm{~min}$ ), particle sizes of dried mango peels powder (particle sizes 600, 425, 300 and $212 \mu \mathrm{m}$ ), solid (g) to water (ml) ratio (1:10, 1:20, 1:30, 1:40 and 1:50), and $\mathrm{pH}$ of solution (2, 4, 6 and 8). After extraction, the extracted sample was be filtered through filter paper (No.1) and evaporated using a rotary evaporator (Buchi, Switzerland), then prepared for total phenolic content analysis same as soxhlet extraction.

\section{F. Determination of Total Phenolic Content}

Total phenolic content was measured by Folin-Ciocalteau method following the methodology proposed by Singleton and Rossi (1965) [11]. A sample of $0.1 \mathrm{ml}$ was mixed with $7.9 \mathrm{ml}$ of water. Then, Folin-Ciocalteau reagent $(0.5 \mathrm{ml})$ was added and allowed to withstand for $5 \mathrm{~min}$. Sodium carbonate $(20 \% \mathrm{w} / \mathrm{v} ; 1.5 \mathrm{ml})$ was then added to the mixture. After shaking, the mixture was incubated for $90 \mathrm{~min}$. The absorbance was measured at $725 \mathrm{~nm}$ using a spectrophotometer. Different concentrations of gallic acid were used for the standard curve and final results were expressed as milligrams of gallic acid equivalents (GAE) per $1 \mathrm{~g}$ of dry weight (DW).

\section{G. Statistical Analysis}

The results were expressed as mean of triplicate determination \pm standard deviation.

\section{RESULTS AND DISCUSSION}

Extraction of bioactive compounds from mango peels using soxhlet and SCW extraction was comparative with total phenolic content as GAE as follows:

\section{A. Soxhlet Extraction}

The effect of extraction time on the total phenolic content during soxhlet with $95 \%$ ethanol extraction at boiling point $\left(78.3^{\circ} \mathrm{C}\right)$ was studied as shown in Fig. 1 . The yield of phenolic compounds increased with increasing of extraction time from 0.5 to $4 \mathrm{~h}$ in the range of 17.23-25.13 mg GAE / $\mathrm{g}$ DW. The longer extraction times, the higher solubility of ethanol extracted phenolic compounds from mango peels. The maximum total phenolic content was $25.13 \mathrm{mg}$ GAE /g DW at extraction time of $4 \mathrm{~h}$.

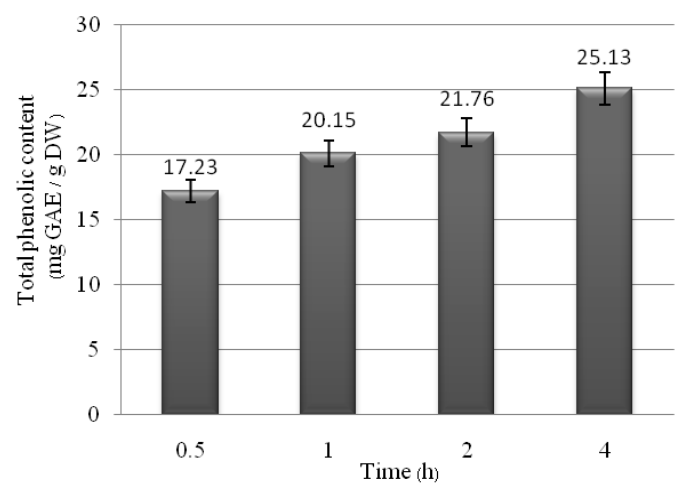

Fig. 1. The phenolic compounds extraction by soxhlet ethanol extraction

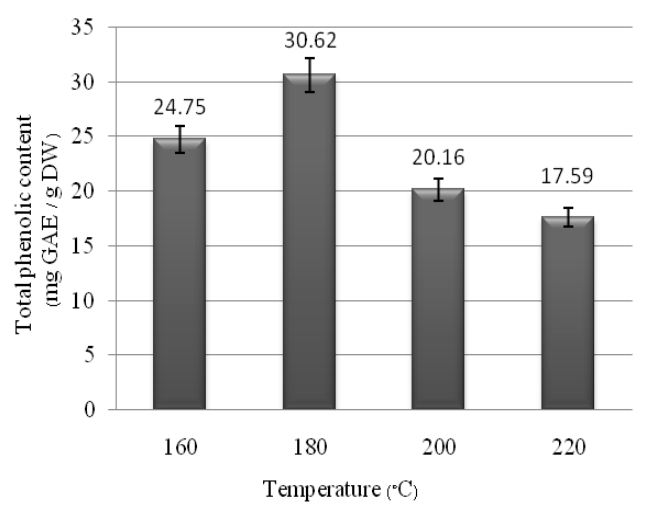

Fig. 2. The effect of extraction temperature on TPC of mango peels extracts.

\section{B. Subcritical Water Extraction (SCW Extraction)}

\section{1) The effect of extraction temperature}

SCW extraction of phenolic compounds from mango peels was carried out at $160-220{ }^{\circ} \mathrm{C}$ for $60 \mathrm{~min}$ with a solid to water ratio 1:40. As described in Fig. 2, the temperature could affect phenolic compounds extraction. Total phenolic contents increased with rising of extraction temperature from 160 to $180{ }^{\circ} \mathrm{C}$, then decreasing from 180 to $220^{\circ} \mathrm{C}$. Also, it showed that total phenolic contents increased from $24.75 \mathrm{mg}$ GAE /g DW to the maximum as $30.62 \mathrm{mg} \mathrm{GAE} / \mathrm{g} \mathrm{DW}$ at $180{ }^{\circ} \mathrm{C}$ as a result of increased solubility of phenolic compounds in 
water with higher temperature. After that the total phenolic content decreased at above $180{ }^{\circ} \mathrm{C}$, possibly due to degradation of phenolic compounds. Therefore, the high temperature extraction improved the efficiency of the extraction since heat renders the cell walls permeable, increased solubility and diffusion coefficients of the compounds to be extracted and decreased the viscosity of the solvent. However, excessive temperature may degrade phenolic compounds [12].

\section{2) The effect of extraction times}

The effect of different extraction times (30, 60, 90 and 120 $\mathrm{min}$ ) on phenolic compounds extraction from mango peels are presented in Fig. 3. All extractions was carried out at $180{ }^{\circ} \mathrm{C}$ with a solid to water ratio $1: 40$. In these result, increasing of the extraction times from 30 to $90 \mathrm{~min}$ increased the yield of phenolic compounds from 13.78 to $35.96 \mathrm{mg} \mathrm{GAE} / \mathrm{g}$ DW. Further increasing the extraction time from 90 to120 min. resulted decreasing of phenolic compounds yield. Decreasing of total phenolic content was due to degradation of phenolic compounds [13]. The maximum total phenolic compounds (35.96 mg GAE / g DW) could be observed at $90 \mathrm{~min}$.



Fig. 3. The effect of extraction time on TPC of mango peels extracts.

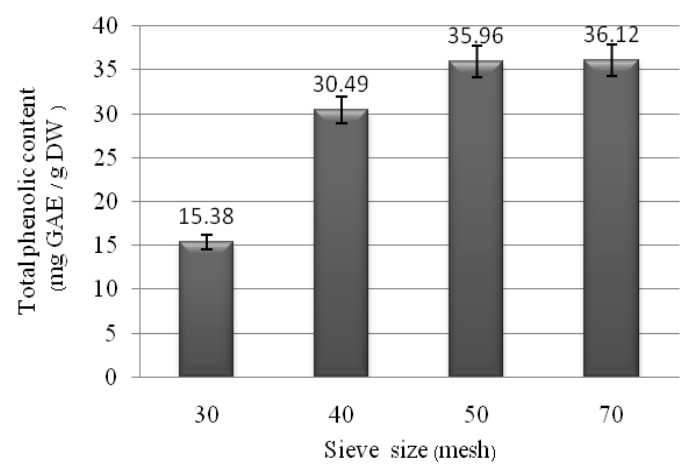

Fig. 4. The effect of material particle sizes on TPC of mango peels extracts.

\section{3) The effect of material particle size}

The result of phenolic compounds extraction using subcritical water extraction at different material particle sizes of $30,40,50$ and 70 mesh $(600,425,300$, and $212 \mu \mathrm{m})$ with $180{ }^{\circ} \mathrm{C}, 90 \mathrm{~min}$ is demonstrated in Fig. 4. This result indicated that material particle size influenced total phenolic compounds in the extracts, decreasing of material particle size increased the total phenolic contents from 15.38 to $36.12 \mathrm{mg}$ GAE / g DW. This result was consistent with the results report from Pumklam et al. [14]. They studied the effect of material particle size on phenolic compounds extraction from mangosteen peel and found that the small material particle size (60 mesh) resulted in increasing of total phenolic contents. Total phenolic contents increased rapidly in material particle size of 30 to 50 mesh and a little change was observed at 50 to70 mesh. The maximum total phenolic content $(36.12$ $\mathrm{mg} \mathrm{GAE} / \mathrm{g} \mathrm{DW}$ ) was observed at 70 mesh. The increasing of total phenolic content was due to increasing of contact surface area between material and solvent as well as increasing of diffusivity of material in solvent [15].

\section{4) The effect of solid to water ratio}

The impact of solid to water ratio on phenolic compounds extraction using subcritical water extraction was studied with five ratios $(1: 10$ to $1: 50)$ at $180{ }^{\circ} \mathrm{C}, 90 \mathrm{~min}$. The result was demonstrated in Fig. 5. Overall, the experimental results showed that solid to water ratio had significant effect on total phenolic content, it was increased with increasing with solid to solvent ratio. Total phenolic content increased rapidly in solid to water ratio from 1:10 to $1: 40$ and increased slightly in solid to water ratio from 1:40 to 1:50. The highest amount of total phenolic content (40.86 mg GAE/g DW) was obtained for solid to water ratio of 1:50. The increasing in total phenolic content due to the high amount of solvent could easier dissolved than extraction at low solvent [16]. The increase of total phenolic content is consistent with mass transfer principle; the driving force during mass transfer is the concentration gradient between the solid and the liquid, which is greater when a higher solvent to solid ratio is used [17].



Fig. 5. The effect of solid to water ratio on TPC of mango peels extracts.

\section{5) The effect of $\mathrm{pH}$}

The effect of extraction time on total phenolic content was investigated at various $\mathrm{pH} 2,4,6$, and 8 as shown in Fig. 6, the $\mathrm{pH}$-values affected the total phenolic content. The total phenolic content ranged from 34.15 to $50.25 \mathrm{mg}$ GAE / g DW. The extraction yield of phenolic compounds increased as the $\mathrm{pH}$ values increased from 2 to 4 , but it decreased as the $\mathrm{pH}$ values higher than 4 were used. The maximum total phenolic content (50.25 mg GAE / g DW) was observed at pH 4 and consistent with the results from [18]. They studied the effect of various on the extraction yield of phenolics from litchi fruit pericarp tissue and found that the maximum total phenolic content was observed at $\mathrm{pH}$ 4. The increased extraction yield of phenolics from under the low $\mathrm{pH}$ conditions could be due to the inhibition of the enzymatic oxidation of phenolics and/or the maintenance of the phenolics extracted. Because many plant tissues have a high enzyme actitvity that could affect degradation of phenolic compounds. Enzymes present in the sample, principally oxidative enzymes, such as peroxidases, polyphenoloxidases, glycosidases and esterases, 
are liberated during the extraction and promote transformations and degradations of polyphenolic compounds [19].

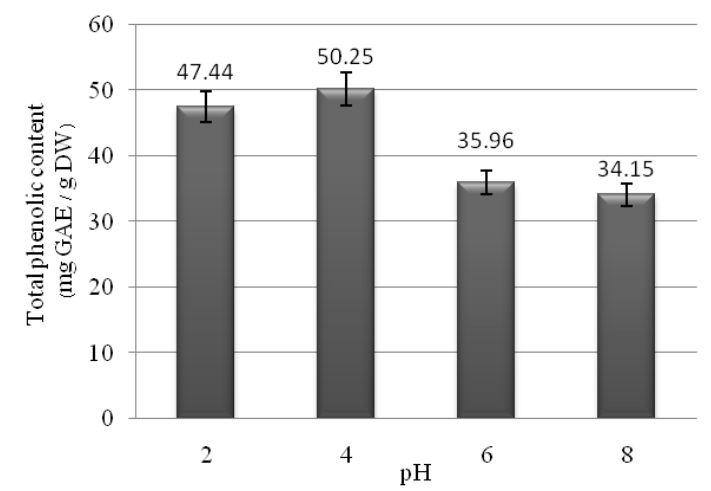

Fig. 6. The effect of $\mathrm{pH}$ in medium on TPC of mango peels extracts.



Fig. 7. Comparison of SCW extraction with soxhlet ethanol extraction.

\section{6) Comparison of SCW extraction with conventional solvent extraction}

Subcritical water extraction $\left(180{ }^{\circ} \mathrm{C}, 60 \mathrm{~min}\right.$, solid to water (ratio of $1: 40$ ) viewed the higher amounts of phenolic compounds from mango peels (30.62 $\mathrm{mg} \mathrm{GAE} / \mathrm{g} \mathrm{DW}$ ) than soxhlet ethanol extraction (21.76 mg GAE / g DW) at boiling point of $95 \%$ ethanol $\left(78.3^{\circ} \mathrm{C}\right)$ at atmospheric pressure for 120 min as shown in Fig. 7. In addition, the extraction time used for SCW extraction was much shorter $(60 \mathrm{~min})$ than that used by conventional solvent extraction $(2 \mathrm{~h})$. Therefore, SCW extraction was an appropriate method for phenolic compounds extraction from plant. Moreover, Subcritical water extraction at condition of $180^{\circ} \mathrm{C}, 90 \mathrm{~min}$, and $\mathrm{pH}$ in solution $=4$ obtained higher amounts of phenolic compounds (50.25 mg GAE/g DW) than soxhlet ethanol extraction at all extraction conditions

\section{CONCLUSION}

Phenolic compounds from mango peels were successful extracted using subcritical water extraction (SCW) was an effective environmentally friendly solvent for extraction of bioactive compounds. Extraction parameters (temperature, time, material particle size, solid to water ratio and $\mathrm{pH}$ in medium) affected the extraction of phenolic compounds from mango peels. The results also demonstrated that extraction yield increased with the temperature increase. However, SCW extraction of phenolic compounds were maximized at $180{ }^{\circ} \mathrm{C}$ and $60 \mathrm{~min}$. Above $180{ }^{\circ} \mathrm{C}$, degradation of phenolic compounds occurred. The SCW extraction at low $\mathrm{pH}$ could increase yield of phenolic compounds. SCW extraction obtained high amount of phenolic compounds from mango peels in shorter time. Furthermore, extraction using subcritical water, it is possible to extract phenolic compounds in pilot and industrial scale to use in the food, pharmaceutical and nutraceutical industries.

\section{ACKNOWLEDGMENT}

The authors thank the National Research Council of Thailand (NRCT) for financial support of this work, Thailand Toray Science Foundation (TTSF) for financial support of this work and conference. We also thank to Faculty of Graduate Studies and for financial support of this conference and Faculty of Engineering, Mahidol University for supported equipment and work place.

\section{REFERENCES}

[1] R. Khonkarn, S. Okonogi, C. Ampasavate, and S. Anuchapreeda, "Investigation of fruit peel extracts as sources for compounds with antioxidant and antiproliferative activities against human cell lines," Food and Chemical Toxicology, vol. 48, pp. 2122-2129, 2010.

[2] M. Friedman and C. Levin, "Analysis and biological activities of potato glycoalkaloids, calystegine alkaloids, phenolic compounds and anthocyanins. In J. Singh, \& L. Kaur (Eds.)," Advances in Potato Chemistry and Technology, pp. 127-161, 2009.

[3] G. Andrich, F. Stevanin, A. Zinnai, F. Venturi, and R. Fiorentini, "Extraction kinetics of natural antioxidants from potato industry by-products. France," in the 6th International Symposium on Supercritical Fluids, pp. 159-163, 2003.

[4] P. S. Pushp, D. A. Marleny, and Saldana, "Subcritical water extraction of phenolic compounds from potato peel," Food Research International, vol. 44, no. 8, pp. 52-2458, 2011.

[5] C. M. Ajila, K. A. Naidu, S. G. Bhat, and U. J. S. P. Rao, "Bioactive compounds and antioxidant potential of mango peel extract," Food Chemistry, vol. 105, no. 3, pp. 982-988, 2007.

[6] P. Maisuthisakul and M. H. Gordon, "Antioxidant and tyrosinase inhibitory activity of mango seed kernel by product," Food Chemistry, vol. 177, no. 2, pp. 332-341, 2009.

[7] S. Akarapach, "Laboratory and pilot scale extraction of mangosteen pericarp using novel technique," M. S. thesis, Dept. Chem. Eng., Mahidol Univ., Bangkok, Thailand, 2012.

[8] M. Herrer, A. Cifuentes, and E. Ibanez, "Sub and supercritical fluid extraction of functional ingredients from different natural sources: plants, food-by-products, algae and microalgae - a review," Food Chemistry, vol. 98, pp. 136-148, 2006.

[9] L. He, X. Zhang, H. Xu, F. Yuan, and Z. Knez, "Subcritical water extraction of phenolic compounds from pomegranate (Punica granatum L.) seed residues and investigation into their antioxidant activities with HPLC-ABTS assay," Food and Bioproducts Processing, vol. 90, no. 2, pp. 215-233, 2012.

[10] P. Rangsriwong, N. Rangkadilok, J. Satayavivad, M. Goto, and A. Shotipruk, "Subcritical water extraction of polyphenolic compounds from Terminalia chebula Retz. Fruits," Separation and Purification Technology, vol. 66, pp. 51-56, 2009.

[11] V. L. Singleton and J. A. Rossi, "Colorimetry of total phenolics with phosphomolybdic- phosphotungstic acid reagents," American journal of Enology and Viticulture, vol. 16, pp. 144-158, 1965.

[12] G. Fausto and P. Vincenzo, "Temperature and solvent effects on polyphenol extraction process from chestnut tree wood," Chemical Engineering Research and Design, vol. 89, pp. 857-862, 2011.

[13] D. R. D. Sotillo, M. Hadley, and E. T. Holm, "Phenolics in aqueous potato peel extract: Extraction, identification and degradation," Journal of Food Science, vol. 59, pp. 649-65, 1994.

[14] P. Ruedeemas and S. Prasong, "The Effect of Particle Size on Antioxidant Capacity of Mangosteen Peel Extract," in Proc. 4th Asean Food Conf., 2011, pp. 728-732.

[15] M. S. Giao, C. I. Pereira, S. C. Fonseca, M. E. Pintado, and F. X. Malcata, "Effect of particle size upon the extent of extraction of antioxidant power from the plants Agrimonia eupatoria, Salvia sp. and Stureja Montana," Food Chemistry, vol. 117, pp. 412-416, 2009. 
[16] E. M. Silva, H. Rogez, and Y Larondelle, "Optimization of extraction of phenolics from Inga edulis leaves using response surface methodology. Sep. Purif," Technol, vol. 55, pp. 381-387. 2007.

[17] A. S. Mohamed and Y. L. Chang, "Optimization of phenolics and dietary fibre extraction from date seeds," vol. 117, pp. 412-416, 2009.

[18] R. Neungnapa, Z. Jia, D. Xuewu, Y. Bao, L. Jianrong, and J. Yueming, "Effects of Various Temperatures and $\mathrm{pH}$ Values on the Extraction Yield of Phenolics from Litchi Fruit Pericarp Tissue and the Antioxidant Activity of the Extracted Anthocyanins," Int. J. Mol. Sci, vol. 9, vol. 1333-1341, 2008.

[19] J. R. Li and Y. Jiang, "Litchi Flavonoids: Isolation, Identification and Biological Activity,” Molecules, vol. 12, pp. 745-758, 2007.
Surawirh Tunchaiyaphum was born in May 30 1989. He got his bachelor's degree in Food Engineering from King Mongkute Institute of Technology Ladkrabang (KMITL), between 2007 to 2010, he got his master of engineering program in integrated chemical engineering. 